\title{
Anillo Primavera. Perspectivas en la gestión de la zona de amortiguamiento del bosque La Primavera desde la visión de los paisajes culturales
}

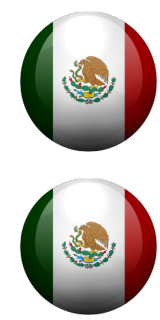

\section{Pedro Alcocer Santos}

Arquitecto, Doctorando en la UPC [España]. Docente en el Taller de Diseño de Espacio Público y Paisaje de la Escuela de Arquitectura del Instituto Tecnológico y de Estudios Superiores de Occidente (ITESO) de la Universidad Jesuita de Guadalajara. Tlaquepaque [Jalisco] México. <pedroalcocer@iteso.mx>

\section{Sandra Valdés Valdés}

Arquitecta, Doctoranda en la UPC [España]. Docente de la Escuela de Arquitectura del Instituto Tecnológico y de Estudios Superiores de Occidente (ITESO) de la Universidad Jesuita de Guadalajara. Tlaquepaque [Jalisco] México.<sandravaldes@iteso.mx>

\section{Resumen}

En este artículo se plantea la necesidad del bosque La Primavera, Reserva de Biosfera MAB UNESCO en Guadalajara, Jalisco, de contar con una zona de amortiguamiento y transición, y cómo los criterios para el desarrollo de esta zona parten de su entendimiento como Paisaje Cultural. En este sentido se buscan puntos en común para la gestión y desarrollo territorial de Reservas de Biosfera y Paisajes Culturales. La conservación del bosque La Primavera requiere un cambio de paradigma en donde bosque y ciudad se visualicen como componentes opuestosse $r$ pero al mismo tiempo complementarios. Se trata de una investigación aplicada surgida de la universidad ITESO y se estructura bajo el modelo de Think Tank que involucra sociedad, gobierno y academia.

\section{Palabras clave}

Reserva de Biosfera. Paisaje Cultural. Bosque La Primavera.

\section{Primavera Ring. Management perspectives on La Primavera forest buffer zone, from the cultural landscapes approach}

\begin{abstract}
The current article intends to high light the need to implement a buffer zone for La Primavera Forest, Biosphere reserve MaB UNESCO in Guadalajara, Jalisco. The criteria to develop this transition zone is based on understanding this territory as a Cultural Landscape. Seeking common ground betwen Biosphere Reserves and Cultural Landscapes criteria to organize the management and development of the buffer zone. To understand the oponents of city development and forest preservation as complementary elements, a paradigm shift is needed. This is an applied research from the ITESO, and it is structured as a Think Tank that involves society, goberment and academy.
\end{abstract}

\section{Keywords}

Biosphere Reserve. Cultural Landscape. La Primavera forest. 


\section{Antecedentes}

El bosque La Primavera se localiza en el costado poniente de la Zona Metropolitana de Guadalajara (ZMG). Es reconocido como Área Natural Protegida por el gobierno de México y como Reserva de Biosfera MAB por la UNESCO.

Cumple una labor indispensable para mantener el equilibrio ecológico del Valle de Atemajac, al grado que una buena parte del microclima de la ZMG depende de su buen estado de conservación. Debido a esta relación de cercanía, desde principios del siglo XX ha existido una continua lucha por la explotación de los recursos productivos del bosque. No se ha respetado el perímetro protegido y constantemente se ha tenido que replantear. Esta continua explotación se ha acelerado en los últimos años con el crecimiento de la mancha urbana, dejando a la zona de protección con un alto grado de vulnerabilidad.

De acuerdo al Plan de Acción de Madrid cada Reserva de Biosfera debería contener tres elementos: una o más zonas núcleo que beneficien de protección a largo plazo y permitan conservar la diversidad biológica, vigilar los ecosistemas y realizar investigaciones. Una zona de amortiguamiento que circunda las zonas núcleo o colinda con ellas junto con una zona de transición flexible, que puede comprender actividades agrícolas, de asentamientos humanos. Alrededor del mundo existen más de 600 Reservas de Biosfera MAB UNESCO, el 98\% de ellas han tenido avances en la consolidación de su zona de amortiguamiento y transición. El bosque La Primavera, está en el $2 \%$ de las reservas que no ha avanzado en este sentido. (UNESCO MaB 2008-2013).

Desde este punto de vista, el borde del bosque es la parte más olvidada del problema. Esta zona conforma una importantísima área de absorción de agua, cuenta con extensos cauces naturales que dotan del $35 \%$ del agua que se consume en la ZMG. Este territorio se está convirtiendo en "tierra de nadie", al mando de la especulación inmobiliaria. Definitivamente de continuar este paradigma de desarrollo y si continúa el ritmo de crecimiento actual en las próximas dos décadas estará construido más del $80 \%$ del perímetro, y muy probablemente represente una condena para la supervivencia del bosque y su oportunidad de establecer un desarrollo sustentable que mantenga una relación sana con la ciudad.

En contraparte, la mayor fortaleza de este borde es su identidad territorial. En él se asientan 25 localidades históricas que en algún momento florecieron por los recursos que el bosque les ofreció. Conforman un sistema de poblaciones equidistantes, perimetrales al bosque, bastante identificable. Dicho sistema define el ámbito territorial de nuestro estudio que propone el espacio para la consideración de una zona de fragilidad ambiental cuyos criterios de desarrollo podrían abonar a la consolidación de la zona de amortiguamiento del Bosque La Primavera.

\section{Anillo Primavera}

La propuesta del proyecto Anillo Primavera es el acompañamiento en la consolidación del área de amortiguamiento y transición, a partir del entendimiento de esta zona como un Paisaje Cultural, desde la estructura de Think Tank que permita la participación de gobierno, sociedad y academia en su discusión e implementación. Ha surgido de la universidad ITESO y han participado más de 70 alumnos, así como un grupo de profesores.

Bajo la hipótesis que los bordes del bosque La Primavera representan una gran oportunidad para aprovechar el gran recurso natural, cultural y territorial para un desarrollo sustentable en la zona metropolitana de Guadalajara. En la medida en que se reconozca una zona de amortiguamiento que requiere una especial atención, podrán ser compatibles el Área Natural Protegida y la zona metropolitana. De lo contrario el bosque corre un gran peligro de desaparecer por el progresivo ahorcamiento que se ha acelerado en los últimos años. Así mismo la zona metropolitana corre el riesgo de perder un gran potencial de desarrollo.

El objetivo que ha conducido la investigación va en el sentido de identificar las singularidades del territorio como medio para establecer una serie de herramientas para su desarrollo territorial. 
En este sentido el entendimiento de los valores patrimoniales de los bordes del bosque abren un campo de investigación para establecer criterios para el desarrollo territorial en Reservas de Biosfera desde la mirada de los Paisajes Culturales.

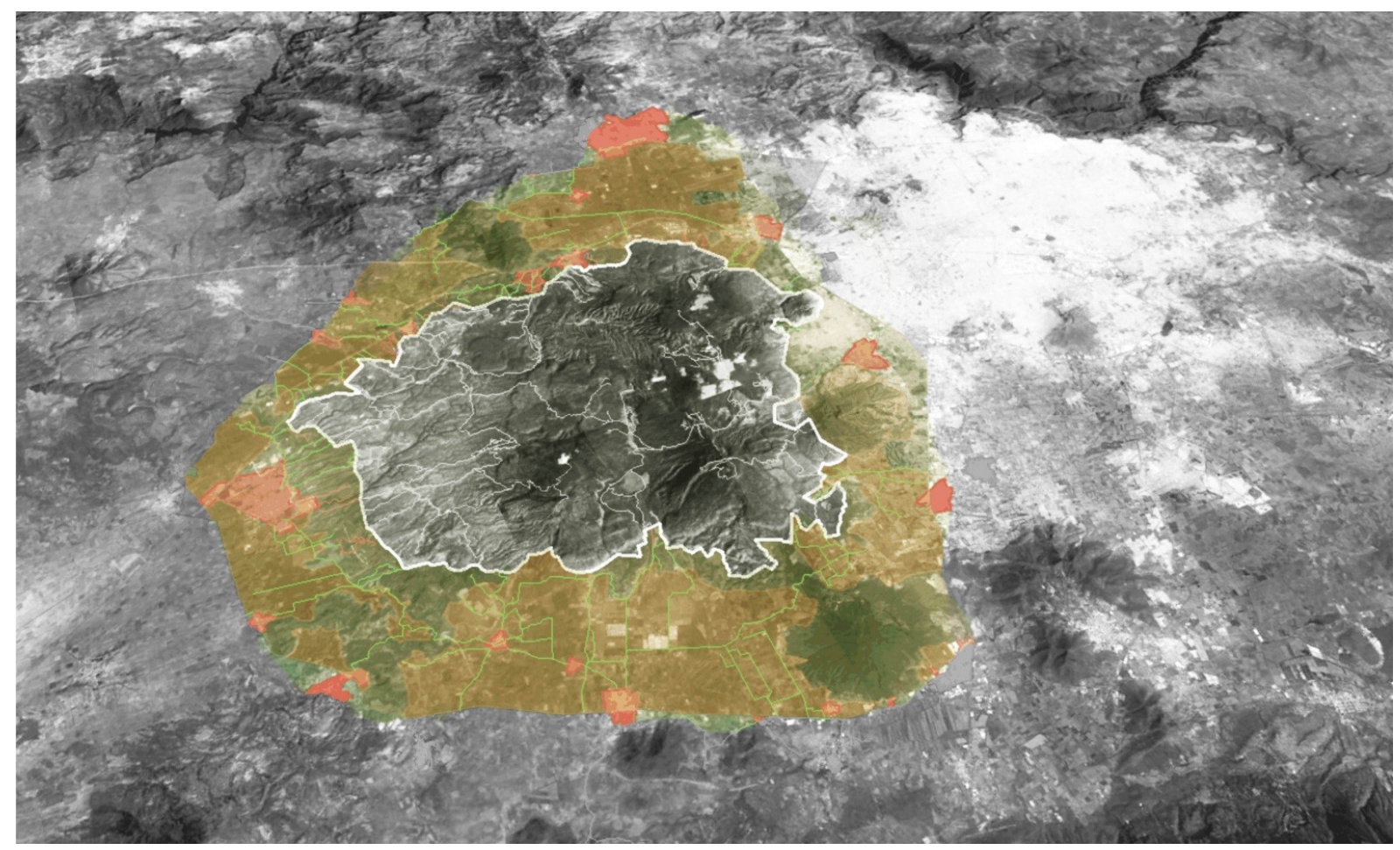

Figura 1. Sistema de poblaciones alrededor del bosque La Primavera. En amarillo destaca la zona de estudio, en naranja se destacan los poblados históricos, en blanco se destaca la ZMG.

\section{Paisajes Culturales y Reservas de Biosfera: un camino en común}

\subsection{Marco de referencia}

Paisaje Cultural se entiende como un concepto complejo que aborda las relaciones de las actividades humanas con su medio ambiente. En este tema convergen intereses comunes a distintas disciplinas y a distintas instituciones. En los últimos años ha resultado útil para englobar en un mismo concepto la amplitud de valores reconocidos en el patrimonio cultural, integrando además una visión interesada en su papel como agente de desarrollo ${ }^{1}$.

Los Paisajes Culturales se han convertido en el concepto que puede explicar las amplias interrelaciones del patrimonio cultural además de sus nuevos alcances participando en el desarrollo de comunidades. De tal forma en la noción contemporánea de Paisaje Cultural se imprime un componente simbólico, además de los componentes espaciales y temporales, los Paisajes Culturales, además de asumir un interés explicativo, mantienen un ingrediente de participación. Se han convertido en un instrumento legal de protección, pero también se han interpretado como un agente de desarrollo²

Muchas veces están ocultos tras la realidad del territorio, y la labor de descifrarlos requiere un trabajo audaz. Entendiendo el patrimonio desde sus relaciones territoriales, podríamos establecer

\footnotetext{
${ }^{1}$ Instituciones como la UNESCO, el Consejo de Europa, y el National Park Service de Estados Unidos tienen definiciones muy especificas sobre el término. En término generales los Paisajes Culturales, desde una aproximación con intereses institucionales, se han convertido en un medio para lograr unos objetivos concretos, vinculadas a estrategias relacionadas con la interpretación, protección y gestión del patrimonio cultural.

${ }^{2}$ Las primeras referencias al término se hicieron desde finales del siglo XIX por geógrafos alemanes. Desde entonces han aparecido diversas aproximaciones desde ámbitos académicos y políticos, aportando componentes que abordan la diversidad de ángulos con los cuales se puede entender el término.
} 
una aproximación más concreta a los Paisajes Culturales como territorios con una identidad singular y claramente reconocible, como alternativa de desarrollo (Sabaté, 2003).

Además de ser construcciones humanas, son el medio cotidiano en el que poblaciones viven y se sostienen, no son zonas arqueológicas carentes de vida propia que describen la forma de subsistencia de los antepasados, por el contrario, son escenarios vivos en los que se reconoce un proceso evolutivo y cultural. Cualquier intervención, por lo tanto, debe involucrar una mirada funcional del paisaje, reconociendo sus relaciones históricas, pero además anticipando los retos que plantea un nuevo paradigma de desarrollo relacionado con el patrimonio cultural.

Es preciso, por lo tanto establecer un reconocimiento específico de una forma de interpretar los valores territoriales del patrimonio cultural o los Paisajes Culturales, desde una óptica dinámica. En esta mirada amplia de los Paisajes Culturales se puede entender el caso de las Reservas de Biosfera como concepto que pretende empatar el desarrollo y la conservación. En los últimos años el concepto de Reserva de Biosfera ha evolucionado para ser parte del desarrollo de las comunidades y no solamente una reserva intocable. Las reservas de biosfera de la UNESCO promueven el equilibrio de intereses entre la protección ambiental y la economía y favorecen la coexistencia del hombre y de la naturaleza (Guevara).

Desde este punto de vista el enfoque de los Paisajes Culturales puede tener puntos muy importantes en común en el desarrollo y gestión de las zonas de amortiguamiento y transición de Reservas de Biosfera, particularmente cuando estas zonas cuentan con recursos patrimoniales importantes. En estos casos la identidad puede convertirse en una alternativa para la intervención.

\section{El Bosque La Primavera: un espacio de encuentro}

\subsection{Metodología}

La zona de influencia que se considera actualmente en el programa de manejo del Área Natural Protegida está determinada por los caminos y carreteras que la rodean. Esta condición deja en una posición muy frágil algunas áreas de la zona protegida ya que no es proporcional la extensión en sus bordes y con la ampliación de la red carretera se irá acercando cada vez más al polígono protegido.

Quizá un criterio más coherente, lógico y eficaz para determinar el área, sea remitirnos a la identidad territorial del sitio. Interesa en este tema principalmente identificar los patrones de asentamiento originales. Existe un sistema de poblados históricos que se asentaron concéntricamente al bosque. La mayor parte de estas poblaciones tienen un origen prehispánico y dibujan un borde bastante definido.

El estudio del territorio está dividido en 3 etapas de trabajo. La primera contempla un inventario de recursos a partir de 5 visiones: paisaje y territorio, valores patrimoniales, calidad de vida y experiencia de los habitantes, visitantes y gestión. La segunda etapa es un análisis hecho a partir de matrices dafográficas. A partir de los resultados de la segunda etapa se desarrollaron 5 líneas de acción, que derivaron en una serie de manuales de buenas prácticas.

\subsection{Inventario de recursos}

El inventario de recursos es una forma de entender las singularidades del sitio, su identidad, en definitiva reconocer un Paisaje Cultural en los bordes del bosque La Primavera. El territorio de estudio tiene dos grandes características, por una parte su condición periférica y por otra parte su legado patrimonial que nos lleva a entenderlo como un Paisaje Cultural. Su situación periférica describe la condición actual del borde del bosque de la Primavera. Aquel territorio aparentemente inconexo, carente de una estructura definida, olvidado, atacado por un altísimo grado de especulación, un territorio tan diverso, en ocasiones marginal, en el que coexisten zonas de alto valor inmobiliario, zonas industriales y grandes extensiones de producción agraria.

El Paisaje Cultural implica entender las singularidades del sitio, su identidad, pero fundamentalmente

(c) Labor \& Engenho, Campinas [SP] Brasil, v.10, n.2, p.143-156, jan./mar. 2016. 
cómo esta historia ha dejado un legado en su organización espacial. Su situación periférica implica entenderlo como parte esencial de la zona metropolitana, no como el patio trasero.

Los recursos asociados al bosque se explican desde los siguientes filtros:

\subsubsection{Los valores patrimoniales}

En esta zona se identifican diversas capas históricas. Se han reconocido diversos rastros arqueológicos como pirámides, tumbas de tiro, petroglifos, centros ceremoniales que atestiguan su pasado prehispánico. Por otra parte la época de la conquista deja importantes vestigios que formaron parte de las villas franciscanas, siendo éste patrimonio Barroco único en México. La época colonial hereda elementos vinculados a las grandes haciendas agrícolas y ganaderas, que hoy día están en pésimo estado de conservación y gran peligro de desaparecer, vinculadas a ellas existen huellas de sistemas de riego que funcionaron a partir de galerías filtrantes. Así mismo la construcción del sistema de ferrocarriles que pertenece a la época del Porfiriato ha dejado un impacto muy significativo en el territorio, heredando un sistema de vías y estaciones actualmente en desuso.

Esta comunicación le dio un gran auge productivo a la zona después de la revolución, y consolidó grandes territorios para la producción de maíz; particularmente en el Municipio de Zapopan que llegó a ser la zona en donde se produjo más maíz por metro cuadrado de todo el territorio nacional, precisamente por las condiciones del suelo y la gran cantidad de agua que es capaz de absorber. Así mismo, por estas mismas características, la producción de caña es una actividad que ha transformado el paisaje en el municipio de Tala, en donde se han asentado alguno de los ingenios más importantes del occidente del país.

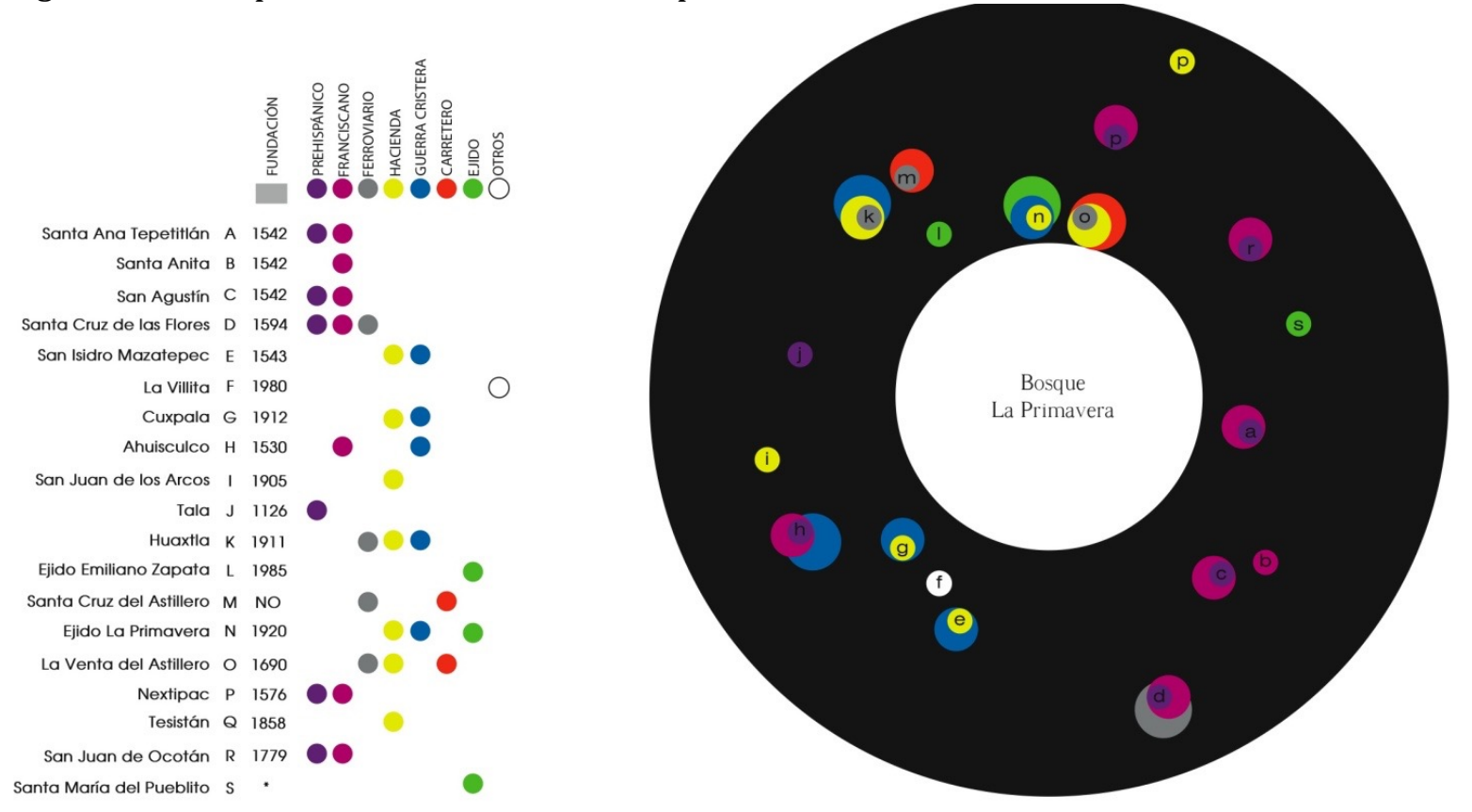

Figura 2. Capas históricas asociadas a los poblados aledaños al bosque La Primavera. Fuente: Elaborado en el marco del proyecto de aplicación profesional Anillo Primavera ITESO.

\subsubsection{Los procesos de transformación del territorio y el paisaje}

El territorio que compone el borde del Bosque de la Primavera es difuso y diverso. A partir de un vasto trabajo de análisis se han identificado más de 20 categorías en su proceso de construcción. Se pretende identificar el proceso de transformación desde sus distintos componentes morfológicos; bosque, parcela agrícola, transformándose en elementos de construcción del paisaje. El estudio de este proceso de construcción implica entender la estructura territorial que está en un proceso muy acelerado de transformación. En donde es posible localizar asentamientos irregulares, fraccionamientos campestres de baja densidad, grandes bloques de vivienda de interés social, corredores industriales así como grandes extensiones de suelo agricola en proceso de transformación. 

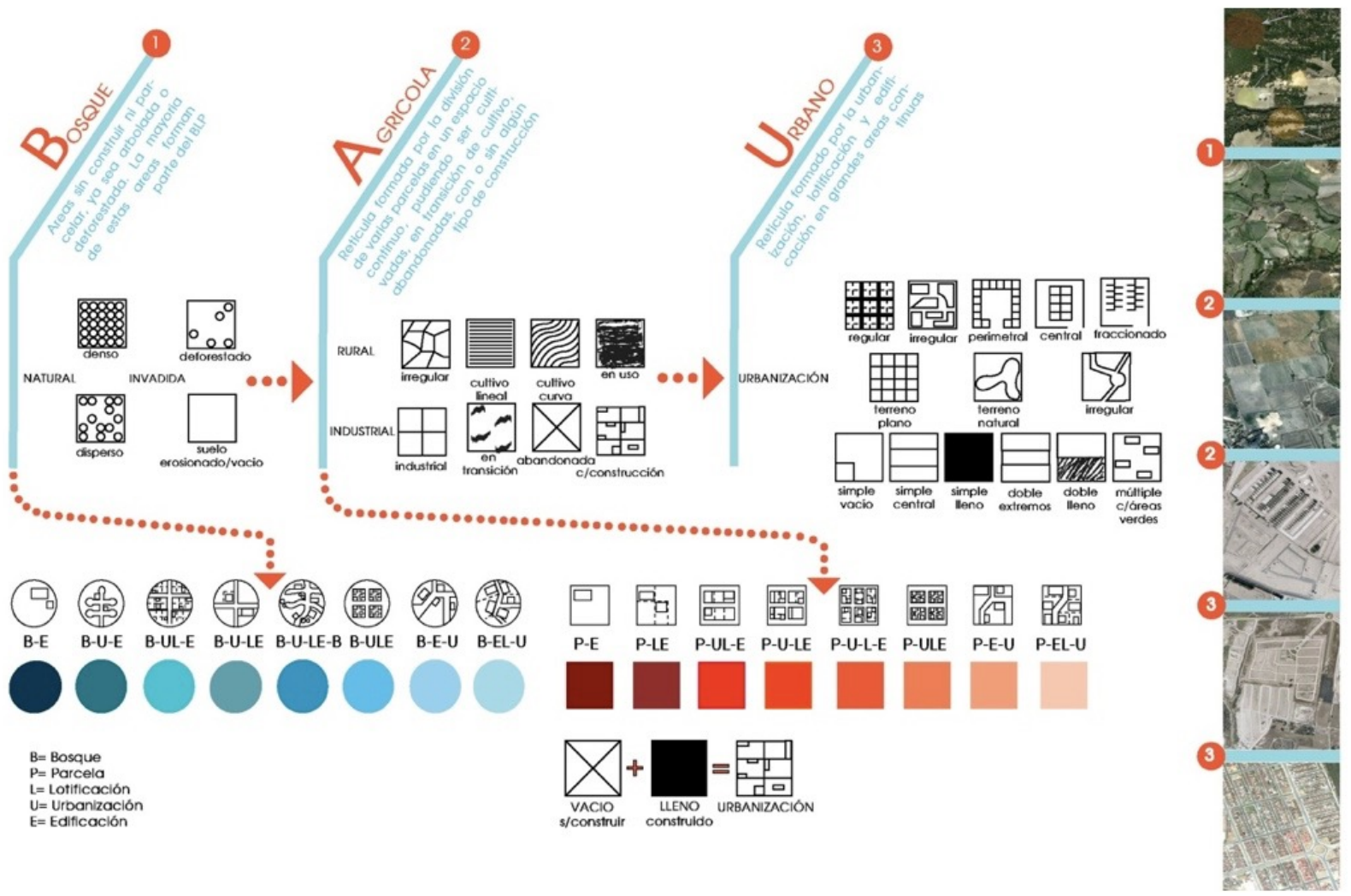

Figura 3. Esquema de procesos de transformación en el territorio. Fuente: Elaborado en el marco del proyecto de aplicación profesional Anillo Primavera ITESO.

\subsubsection{Calidad de vida y experiencia de los habitantes}

Si bien en épocas anteriores existió una conciencia de los habitantes de la zona con sus recursos más próximos, el bosque mismo, hoy día esta conciencia ha ido desapareciendo. La relación de las comunidades con el bosque es cada vez más distante. Esto aunado a la privatización de los espacios directamente vinculados al bosque con la eclosión de fraccionamientos campestres. No es casualidad que los fraccionamientos más representativos se han establecido muy cerca de las comunidades generando una interacción bastante dispareja, unos buscan todos los beneficios de una vida campestre, otros son sus sirvientes. Estos procesos han generado una degradación de la calidad de vida de los habitantes; por una parte en las comunidades originalmente asentadas sufren reiteradas carencias de todo tipo, por su parte los habitantes de los fraccionamientos campestres carecen de todo tipo de servicios cercanos, tienen que desplazarse durante largos trayectos para resolver sus necesidades de trabajo, escuela, ocio y abastecimiento. Esta fractura al mismo tiempo está generando un modelo de organización espacial completamente desarticulado.

\subsubsection{Experiencia de los visitantes}

Las oportunidades que plantea un área natural protegida tan vinculada a un contexto urbano como lo es la zona metropolitana de Guadalajara pueden convertirse en un gran potencial para un desarrollo. Sin embargo existe un gran desconocimiento del sitio y de todos sus recursos asociados. Si bien es cierto que el bosque es un ecosistema muy delicado que debe ser cuidado con bastante recelo para su conservación, también es cierto que lo que no se conoce no se puede proteger. Los visitantes que hasta ahora van al sitio lo hacen por muchas razones y gran parte de los casos no corresponden a las mejores prácticas; tiraderos clandestinos de basura, bancos no autorizados de extracción de materiales (canteras), rutas de ciclistas y motociclistas no autorizados, usos no permitidos al interior del bosque. Así mismo el potencial que tiene el patrimonio antes mencionado genera todo un campo de posibilidades para los visitantes.

\subsubsection{La gestión}

Si bien la zona de influencia del bosque de La Primavera está delineada por este sistema de poblados, no tiene ninguna validez jurídica. Entender este importante enclave como una unidad debe ser fundamental 
para una gestión exitosa del sitio, muchos han sido los esfuerzos. Sin embargo, en la medida en que no exista una coordinación la gestión los resultados difícilmente serán exitosos. Lamentablemente la coordinación metropolitana no ha tomado en cuenta este importante enclave.

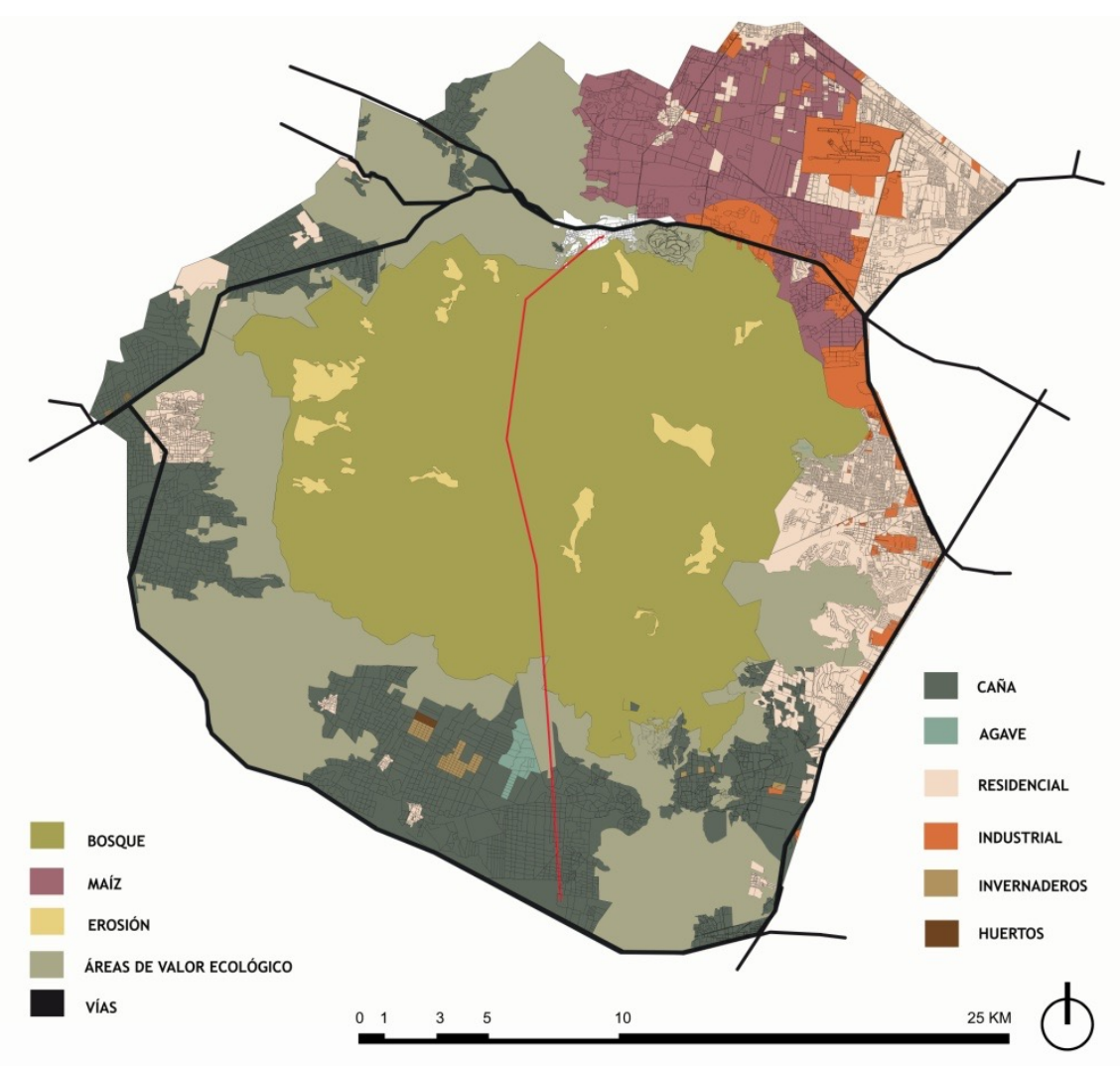

Figura 4. Mapa de utilización del suelo. Fuente: Elaborado en el marco del proyecto de aplicación profesional Anillo Primavera ITESO.

\subsubsection{Matrices Dafográficas}

Esta etapa se construye a partir de matrices DAFO (Debilidades, Amenazas, Fortalezas, Oportunidades), con la particularidad que por cada matriz hecha se hace un mapa para identificar cada uno de los elementos y su ámbito de influencia dentro del territorio. El resultado son una serie de fichas que tienen un mapa de referencia. Para iniciar este proceso se subdividió el territorio en sectores y a cada sector se le asignó una letra, esto para que pudieran funcionar como coordenadas para identificar mejor cada zona y a su vez a cada zona se le pudiera asignar un valor de acuerdo a los criterios DAFO.

Para esta fase se hicieron 4 tipos de matrices:

- Individuales: es una ficha por cada recurso identificado.

- Cruce interno: en esta etapa se cruza la información internamente de cada visión (ver Figura 5).

- Cruce externo: se comparan las conclusiones del cruce interno entre sí (ver Figura 6).

- Mapas resumen: se hacen mapas de conclusiones (ver Figura 7). 


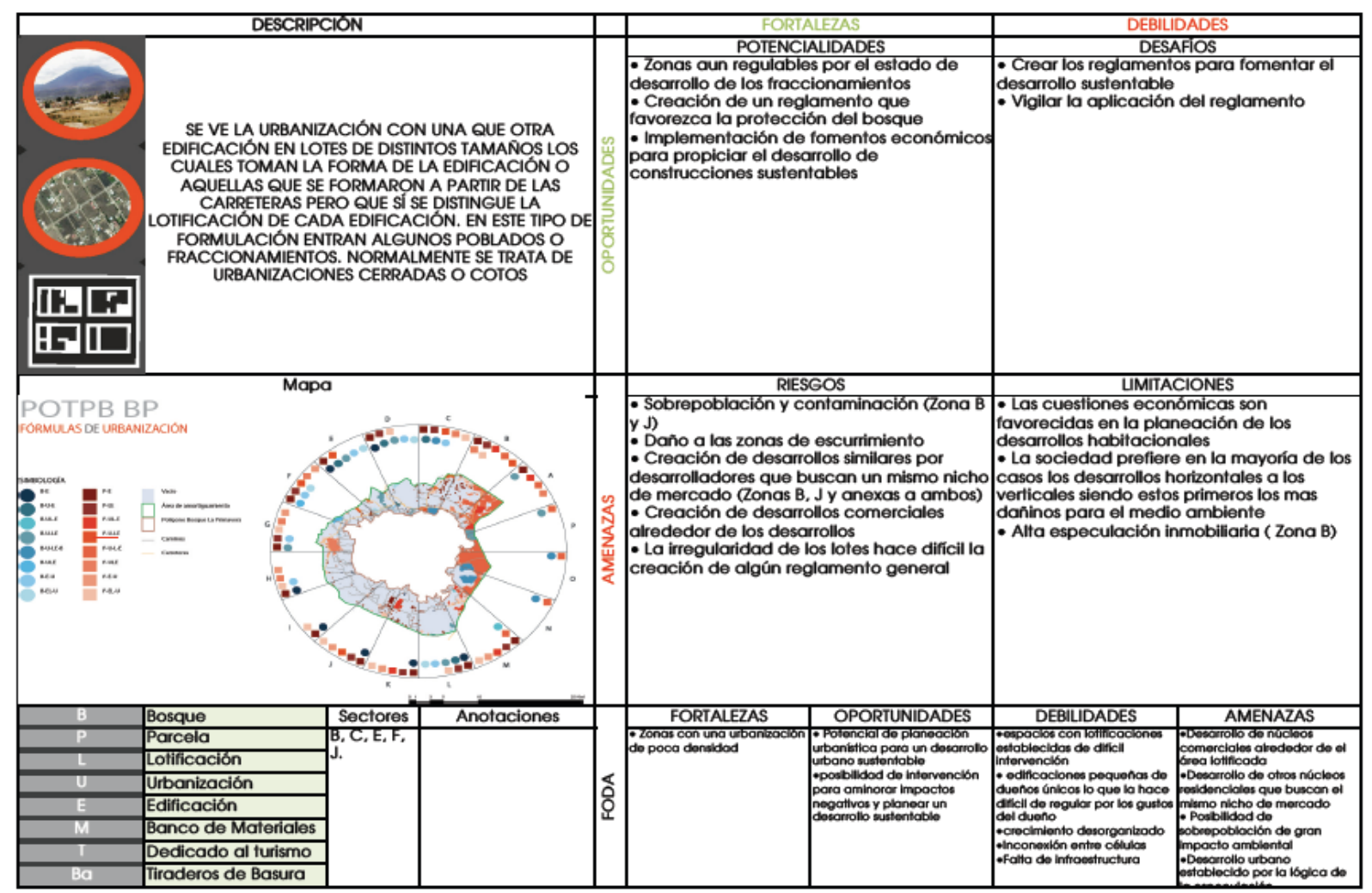

Figura 5. Cruce interno: se cruza las matrices individuales entre sí, dentro de cada visión.

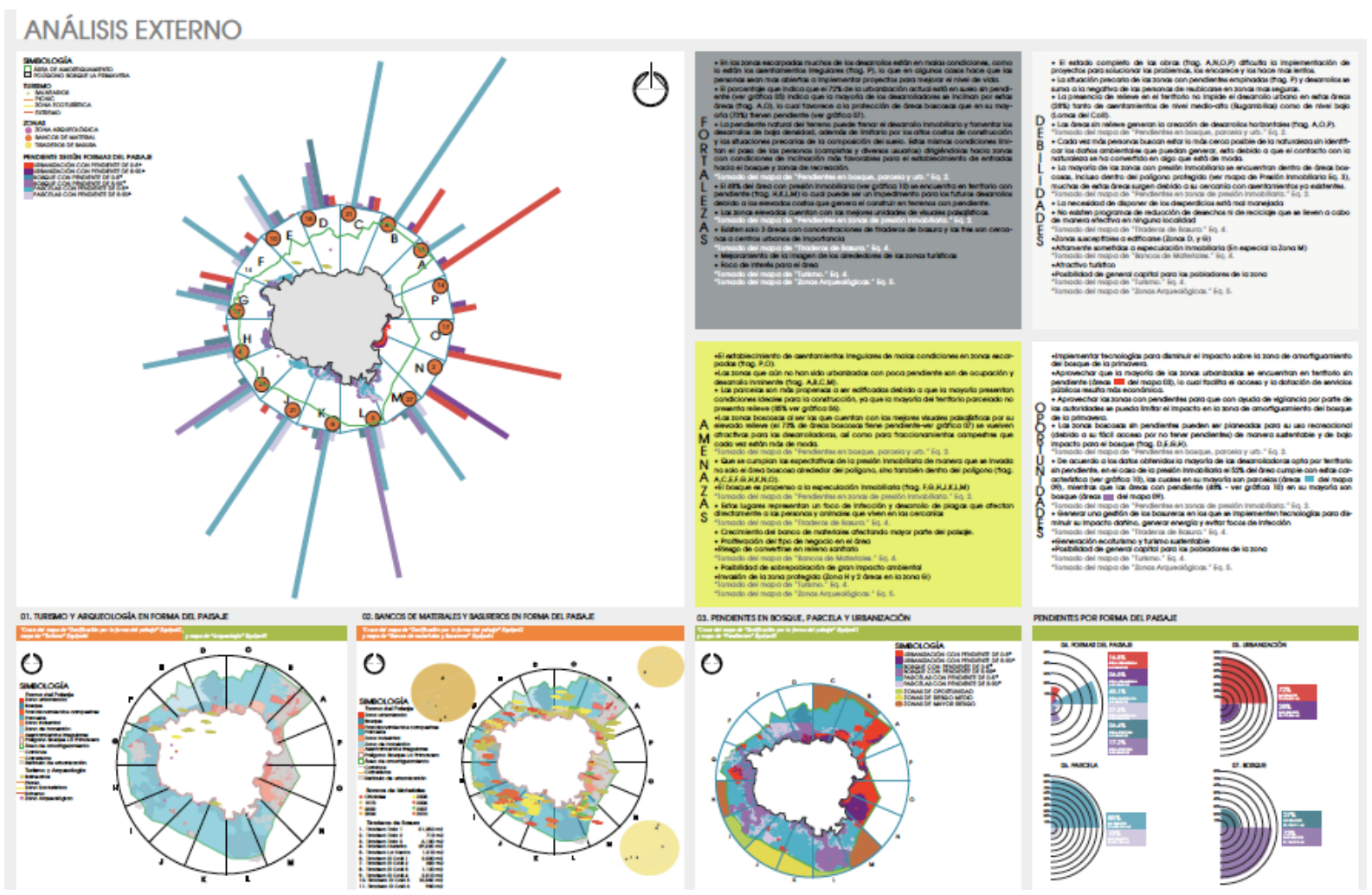

Figura 6. Cruce externo: las conclusiones del cruce internos se comparan entre sí. 


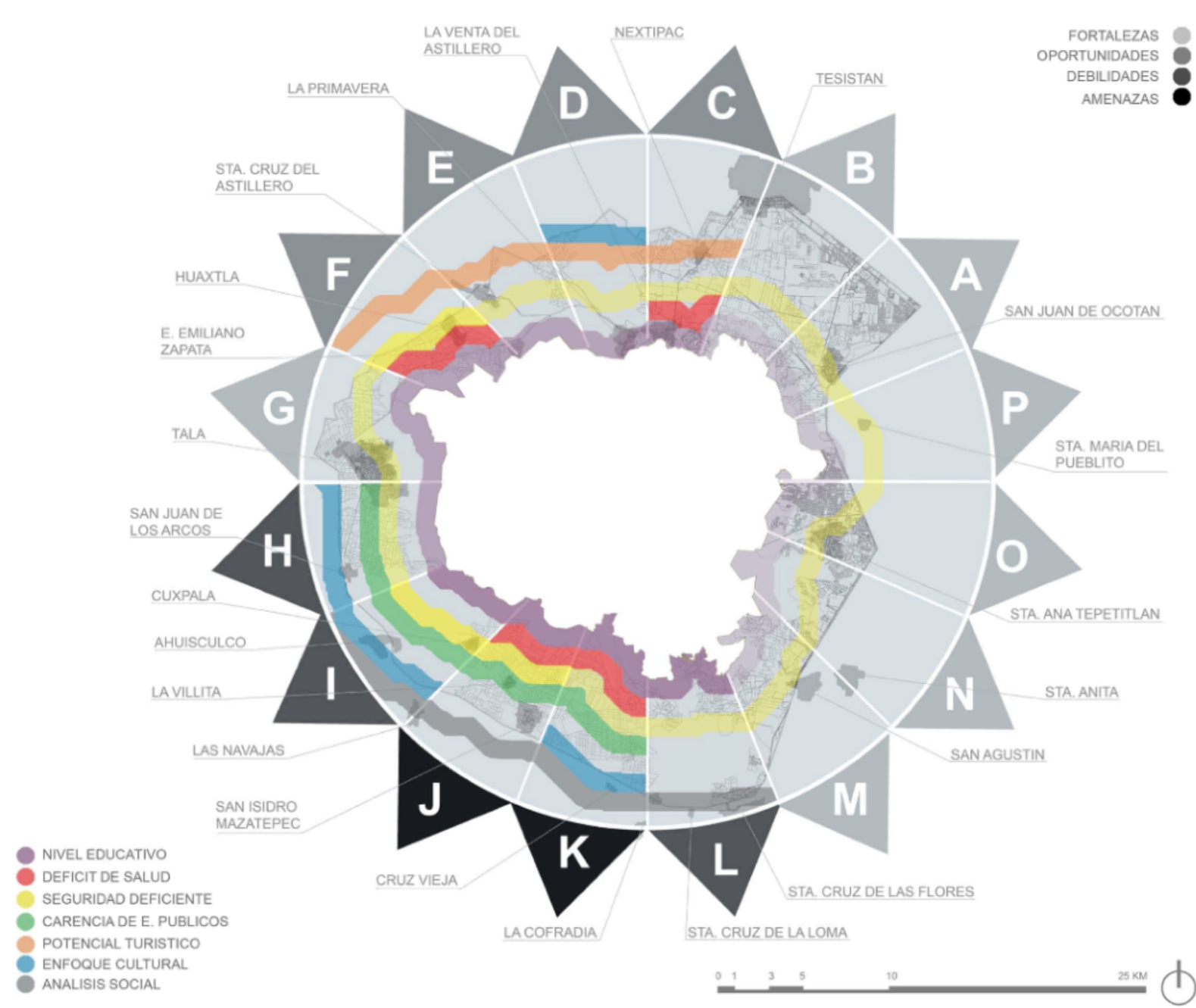

Figura 7. Mapa resumen:

En estos mapas se muestran gráficamente los resultados del cruce del paso 3, formando una gráfica al rededor de la zona afectada, indicando con color los resultados de las comparativas. Identificando con los colores las Fortalezas, Oportunidades, Debilidades y Amenazas, para después identificar las Potencialidades, Riesgos y Limitaciones.

\subsection{Líneas de acción}

En base a los resultados obtenidos en la etapa de análisis, se han identificado algunas líneas estratégicas que deben tomarse en cuenta para el desarrollo de la zona de amortiguamiento:

\subsubsection{Identidad y comunicación}

Una de las grandes amenazas al bosque es la falta de identidad, una encuesta realizada después del incendio del 2005, afectó más de 10,000 hectáreas, arrojó que 7 de cada 10 habitantes de la ZMG no sabe dónde está el bosque La Primavera. Por otro lado, los habitantes de los poblados aspiran a vivir en la ciudad o migrar a Estados Unidos.

En este sentido unos de los pilares fundamentales en la consolidación de la zona de amortiguamiento son la Identidad y la comunicación tomando en cuenta las siguientes consideraciones:

- Identificar, proteger y vincular los paisajes de mayor valor.

- Identificar los patrones de crecimiento urbano idóneos para el desarrollo de cada uno de estos paisajes.

- Integrar las infraestructuras al paisaje.

- Identificar y dar a conocer los valores históricos y culturales del lugar.

- Reconocer y divulgar la importancia del patrimonio natural de la zona. 


\subsubsection{Conectividad}

La distancia entre un poblado y otro es de aproximadamente $5 \mathrm{~km}$, un trayecto caminable para una persona promedio. El desarrollo de zonas habitacionales urbanas, aledañas a los poblados tradicionales ha deteriorado las vinculaciones entre un poblado y otro, aislándolos de infraestructura básica como caminos, escuelas y hospitales. Generando no solamente aislamiento físico sino desvinculaciones sociales.

Por esto resulta importante:

- Vincular a los pobladores como principales agentes de protección.

- Detonar la conectividad física entre poblados es imprescindible para la construcción de la zona de amortiguamiento, para asegurar la vinculación social.

- Proteger y poner en valor el patrimonio cultural de los poblados, asegurando la calidad de vida de las personas.
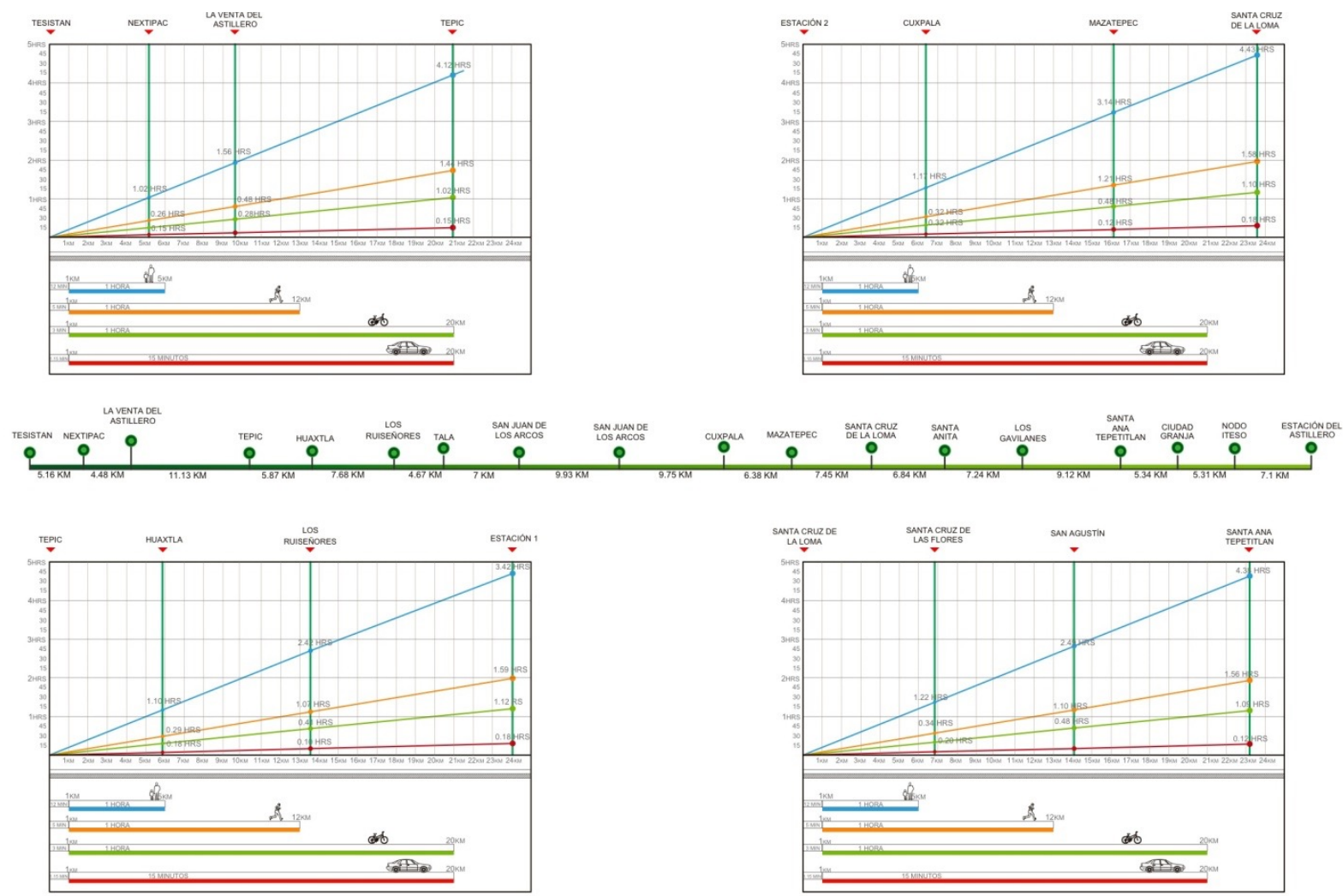

Figura 8. Graficas de tiempo de traslado entre poblados de acuerdo a distintos medios de transporte. Fuente: Elaborado en el marco del proyecto de aplicación profesional Anillo Primavera ITESO.

\subsubsection{Actividades productivas}

La migración, la falta de apoyos gubernamentales, trámites burocráticos complejos, la falta de desarrollo de actividades productivas en el lugar que potencien y vinculen a las personas con los recursos propios, ha provocado el abandono de las tierras de cultivo. La agricultura es una de las actividades productivas en las que se fundamenta la identidad de la zona, su abandono ha provocado alta especulación inmobiliaria, así mismo es la actividad con más susceptibilidad a cambio de uso de suelo y con esto se generado la perdida de importantes zonas de absorción de agua.

Así mismo, una de las principales actividades económicas del lugar es el servicio doméstico a los fraccionamientos que se asientan en las cercanías de los poblados. Al mismo tiempo El decrecimiento poblacional en algunas localidades a causa de la migración y la rápida expansión de la ciudad ha detonado el deterioro de patrimonio histórico de la zona. (Haciendas del porfiriato abandonadas, la capilla de indios del siglo XVI en peligro de desaparecer, la pirámide que quedó en medio de un fraccionamiento) 
Por esto es imprescindible:

- Garantizar la continuidad de la actividad agrícola en la zona.

- Generar nuevas actividades productivas que detonen el reconocimiento y protección del patrimonio histórico y cultural del lugar.

\subsubsection{Infraestructura e integración al paisaje}

La mayor parte de la infraestructura que se construye en los bordes del bosque ignora y amenaza la continuidad del patrimonio natural. A pesar de que en los últimos 15 años se ha urbanizado el $30 \%$ de la zona de estudio, el $70 \%$ carece de planes de desarrollo, esto representa una de las mayores amenazas, pero también representa una gran oportunidad para detonar el cambio de paradigma que se requiere, respecto a la relación bosque-ciudad.

Por esto es importante:

- Proteger y poner en valor el patrimonio natural; particularmente los corredores biológicos, escurrimientos y zonas de absorción de agua.

- Detonar el conocimiento de los recursos para generar identidad en el sitio a partir de un desarrollo endógeno.

- Dar a conocer el valor de la primavera respecto al desarrollo metropolitano.

\subsubsection{Recreación y espacio público}

La mayor parte de los poblados cuenta con muy pocos o muy deteriorados espacio públicos para el ocio y el deporte. Uno de los poblados tradicionales San Juan de Ocotán, está catalogado como una de las zonas más peligrosas de la ZMG. Por otro lado el bosque recibe cada año 300,000 visitantes, superando la capacidad de control de las autoridades del bosque.

Por esto es importante:

- Potenciar el uso recreativo y público de los bordes del bosque de La Primavera.

- Adecuar los espacios públicos existentes.

- Generar nuevos espacios de ocio y deporte en la zona.
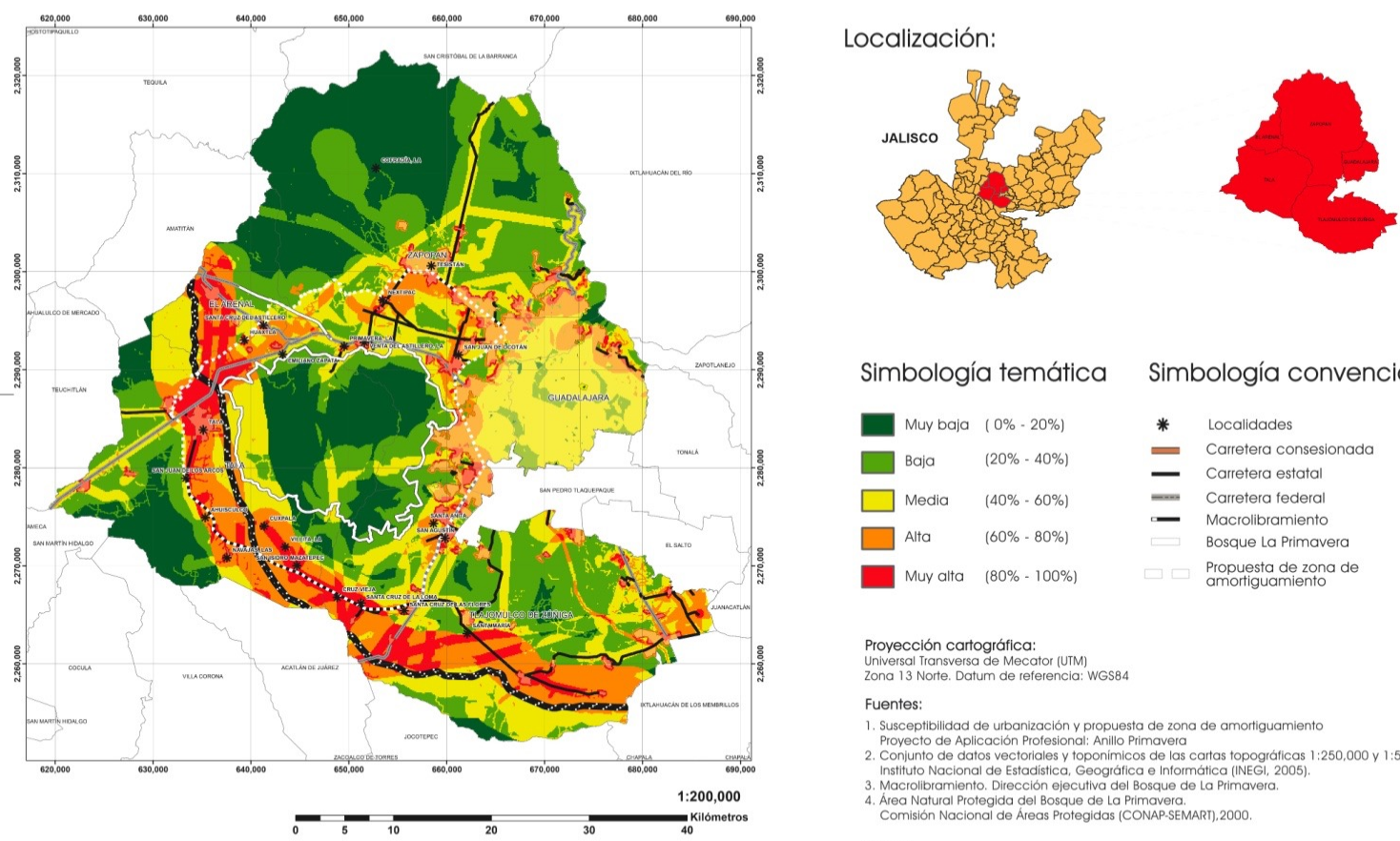

Simbología temática

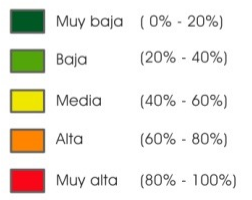

Proyección cartográfica:

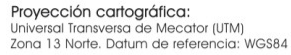

Fuentes:

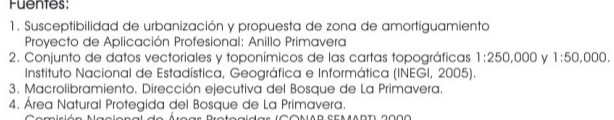

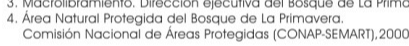

Figura 9. Estudio de álgebra de mapas sobre la susceptibilidad de urbanización en la zona de estudio. Fuente: Elaborado en el marco del proyecto de aplicación profesional Anillo Primavera ITESO. La línea gruesa indica una nueva infraestructura carretera actualmente en construcción, cuyos planteamientos no tomaron en cuenta el impacto sobre el bosque. 
A partir de la revisión de estas líneas estratégicas se han desarrollado 5 manuales de buenas prácticas, cada uno estructurado por cinco capítulos que corresponden a cada una de las visiones del inventario de recursos.

El objetivo de estos documentos es proveer de herramientas para la toma de decisiones que velen por la conservación del bosque a largo plazo por medio de un desarrollo sustentable en su zona de amortiguamiento.

\section{Conclusiones}

Como se mencionó en la hipótesis, los bordes del bosque La Primavera representan una gran oportunidad para aprovechar el gran recurso natural, cultural y territorial. En la medida en que se reconozca una zona de amortiguamiento que requiere una especial atención, podrán ser compatibles el Área Natural Protegida y la zona metropolitana. De lo contrario el bosque corre un gran peligro de desaparecer por el progresivo ahorcamiento que se ha acelerado en los últimos años. Así mismo la zona metropolitana corre el riesgo de perder un gran potencial de desarrollo.

En este sentido se han identificado los siguientes indicadores que intentan esbozar los principales retos y desafíos en el avance de las líneas de acción antes descritas.

\subsection{Identidad, construcción de redes}

Los próximos años representan la diferencia entre trabajar en la conservación o ceder el bosque a la depredación de la mancha urbana. Hasta ahora el bosque sufre las consecuencias de tener un borde con 5 administraciones distintas, cambios de gobierno, desvinculación entre trabajos académicos y una sociedad desorganizada y mal informada. Los actores involucrados tienen que caminar en la misma dirección, a partir de diversos mecanismos y el bosque tiene que ser el centro de las decisiones.

Por lo tanto resulta fundamental, pensar, reflexionar, y actuar en consecuencia. La consolidación de la zona de amortiguamiento para el bosque no puede ser la iniciativa de una persona o una institución. Para tener impacto o influencia en la toma de decisiones, este tiene que ser un trabajo de co-creación, que involucre a la sociedad, gobierno, instituciones educativas y empresas.

\subsection{Cercanía y reconocimiento mutuo como habitantes del bosque}

El sistema de poblados históricos que rodean al bosque, está eficientemente dispuesto. El crecimiento urbano ha colocado barreras físicas y sociales entre estos, deteriorando rápidamente la vinculación bosque-habitantes-ciudad.

Un reto fundamental es establecer mecanismos para que los pobladores se identifiquen como los principales agentes de protección del bosque, así mismo y acercar a las comunidades entre sí para recuperar las relaciones de cercanía preexistentes.

\subsection{Empoderamiento de los habitantes}

El gobierno, los habitantes cercanos y los dueños tanto de las parcelas al interior de bosque, las zonas de absorción de agua, así como enclaves con patrimonio histórico construido, se debaten entre trabajar para su protección o ceder a los intereses económicos que parecen resolver de forma más inmediata la falta de desarrollo económico del lugar.

Un desafío trascendente está en la construcción de un modelo de gobernanza que incluya a todos los actores involucrados y desarrolle un esquema de participación, desde el cual, los principales interesados para la protección de su patrimonio sean los mismos habitantes y dueños del lugar. Un modelo que permita el crecimiento económico del lugar a partir de la sociedad bien organizada para la protección de sus recursos patrimoniales. 


\subsection{Integración de la infraestructura verde y azul al modelo de desarrollo}

La mayor parte de infraestructura desarrollada en las últimas décadas ha impactado negativamente en la calidad de vida de las personas y la protección de patrimonio natural y cultural.

Para contrarrestar este fenómeno se considera importante el reconocimiento de corredores biológicos, zonas de masa vegetal protegidas como infraestructura verde, así mismo escurrimientos, cuerpos de agua y zonas de absorción de agua como infraestructura azul.

\subsection{Construcción social de un cambio de paradigma}

Hasta ahora los planes de desarrollo de la ciudad han ignorado la importancia de la conservación bosque en el desarrollo de la ZMG.

Generar los planes de desarrollo y gestión necesarios que modifique el paradigma de cómo se ha relacionado la ciudad con el bosque es el mayor desafío. Este cambio de paradigma difícilmente saldrá de una iniciativa del gobierno, por el contrario tiene que construirse desde la base social, con la participación de un amplio espectro de la ciudadanía.

\subsection{Discusión}

En definitiva, el proceso que ha iniciado el bosque La Primavera tiene el potencial de integrar los conceptos Reservas de Biosfera y Paisajes Culturales a través de la implementación de mecanismos de gestión que en todo momento velen por la conservación del gran legado patrimonial asociado al bosque como medio de desarrollo para las comunidades. En este sentido las decisiones en este ámbito territorial tendrán que comenzar a tomarse con el bosque como centro.

En este sentido, reconocer un territorio como Paisaje Cultural implica también un reconocimiento de proyecto y gestión del sitio. El proyecto en el Paisaje Cultural implica entenderlo como un texto, un libro abierto a habitantes y visitantes, implica desde la levedad, elaborar un memorial al labrador desconocido (Fowler, 2004).

Para poder seguir los indicadores anteriormente expuestos, el proyecto Anillo Primavera ha avanzado en su estructura de operación y ha tomado como modelo de gestión un Think Tank, que se estructura en tres partes.

Laboratorio de ideas: Es donde se gestan las ideas, metodologías, líneas de acción, y estrategias para consolidar la zona de amortiguamiento del bosque desde una visión científica. En este sentido el laboratorio de Ideas Anillo Primavera desarrolla metodologías para el ordenamiento del Paisaje y el territorio en zonas aledañas a áreas naturales protegidas amenazadas.

Semillero de proyectos: Actúa como un gestor de proyectos vinculando a los actores involucrados para fondear los proyectos emanados del Laboratorio de Ideas, o cualquier ámbito de la sociedad civil y la vida académica, que fomenten el desarrollo de la zona de amortiguamiento. Una de las grandes amenazas al bosque, es la falta de un proyecto definido a corto mediano y largo plazo, asegurar su continuidad a través de cambios administrativos y de gobierno, así mismo alejado de intereses particulares. Ante esta inquietud se busca la constitución de un organismo que vincule la academia, la sociedad, la iniciativa privada y al gobierno, que tenga la oportunidad de cuidar los intereses del bosque.

Observatorio de la Zona de Amortiguamiento: Sistematiza y actualiza la información emanada del laboratorio de ideas con el fin de generar herramientas que faciliten a las autoridades la toma de decisiones para la protección del bosque desde el desarrollo sustentable de su zona de amortiguamiento. Este observatorio también busca trabajar en red con investigadores e instituciones que trabajen en temas similares, buscando el intercambio de experiencias y metodologías.

Falta mucho camino por recorrer sin embargo el tema de la necesidad de esta zona de amortiguamiento ya está instalado en la agenda pública, con el respaldo de instituciones como la 
Cátedra UNESCO en Reservas de Biosfera de la Universidad para la Cooperación Internacional de Costa Rica, así mismo, para el desarrollo formal del semillero de proyectos se ha constituido legalmente Anillo Primavera AC, que actualmente ha sido invitada a pertenecer al consejo ciudadano del OPD para el Bosque La Primavera, que es el organismo que ha creado el gobierno para gestionar el Área Natural Protegida.

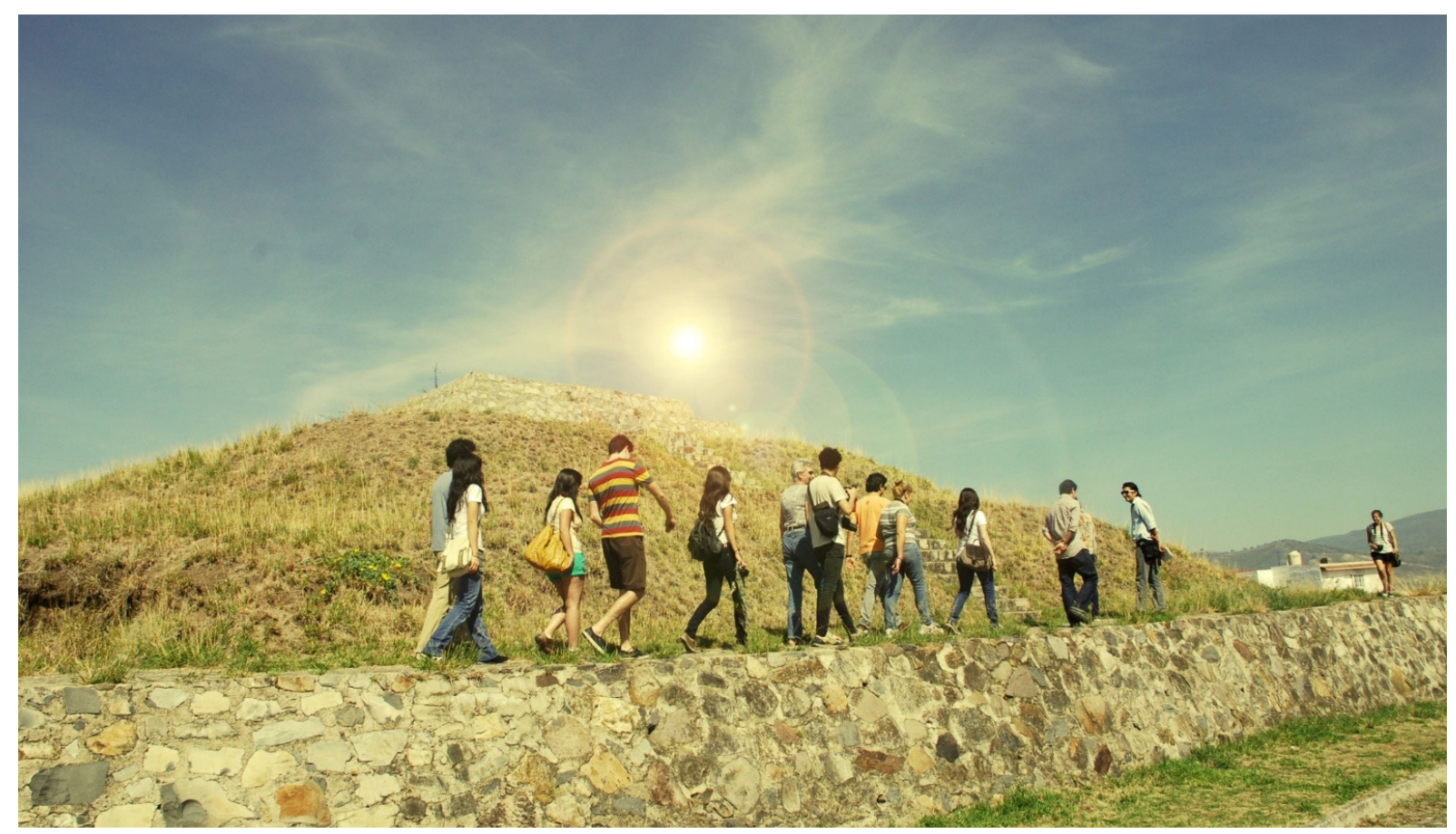

Figura 10. Pirámide el Cortijo en San Agustín.

\section{Referencias}

Brinbaum, C. (n.d.). Protecting Cultural Landscapes. Planing, treatment and Magnament of Historic Landscapes, 36 preservation Briefs, Tecnical Preservation Services, National Park Service.

Calafate Boyle, S. (2003). Patrimonio Cultural: Opción para el desarrollo. Seminario Taller Internacional: Quebrada de Humahuaca: Patrimonio Munidial. Argentina. (en papel).

Fowler, P. (2003). World Heritage Cultural Landscape. 1992-2002. World Heritage Papers 6. UNESCO.

Guevara, S. (2009). El Enfoque Paisajístico en la Conservación: Rediseñando las Reservas para la Protección de la Diversidad Biológica y Cultural en América Latina. Environmental Ethics.

Margalef, R. (1992). En los márgenes de los sistemas ecológicos. Revista UR N 9. (Barcelona).

Ortega Valcárcel, J. (1998) El Patrimonio Territorial: El territorio como Recurso Cultural y Económico. Revista del Instituto de Urbanística de la Universidad de Valladolid. Ciudades 4. "Territorio y Patrimonio".

Plan de Acción de Madrid Para las Reservas de Biosfera (2008). UNESCO Programa de Hombre y Biosfera MAB. Madrid.

Sabaté Bel, J. (2004). Paisajes Culturales: El patrimonio como recurso básico para un nuevo modelo de desarrollo. Revista Urban no 9. (Madrid).

Sauer, C. (1925). The Morphology of Landscape. Univesty of California. In Geography.

Soria y Puig, A., \& Menéndez de Luarca, J. R. (1994). El territorio como artificio cultural. Corografia histórica del norte de la península ibérica. Ciudad y Territorio, № 99, (Madrid). 